\title{
ReCOLlection
}

\section{Commitment and dedication of a Chinese plant physiologist}

\author{
Tingyun Kuang ${ }^{1}$, Ming $\mathrm{Li}^{2}$, Le Kang ${ }^{2}$ \\ ${ }^{1}$ Institute of Botany, Chinese Academy of Sciences, Beijing 100093, China \\ 2 Beijing Institutes of Life Science, Chinese Academy of Sciences, Beijing 100101, China
}

Professor Peisong Tang (Pei-sung Tang), born in 1903, is one of the co-founders of the modern Chinese plant physiology. You might be familiar with some of his academic achievements: he is the first one to discover respiratory enzymes (cytochorome oxidase) in plants; he proved that multiple respiratory metabolic pathways and electron transfers exist in the rice; he is the first one to experimentally prove the existence of carbonic anhydrase in plants; together with Prof. Zhuxi Wang, he used thermodynamical method to illustrate the mechanism of intracellular water movement, which later has been referred to as the "Tang-Wang theory of cellular water potential". You probably also know that he is the first Chinese biologist who published in Nature and Science in 1940 s and 1950s. But there is something about him that you will not learn from his over 200 publications: his commitment, as a Chinese, to his country and his people, and his dedication, as a scientist, in pursuing science and truths.

Peisong Tang received his early education at Tsinghua College from 1917 to 1925, financially supported by the "Boxer Indemnity Scholarship", which came through heavy taxation on the Chinese people. It was why Peisong Tang always felt indebted to his country and his people, and made a commitment of returning home after studying abroad for years. It was also at Tsinghua College where he first showed his interests in biology. After the biology teacher described how the starch stored in the endosperm of a seed converted into a seedling, he raised a question that the teacher could not answer: 'How exactly do unorganized materials like starch become a seedling, something so well-organized and perfectly-structured?' Little did he then know that the question became the starting point of his scientific life.

After graduation from Tsinghua College, Peisong Tang went to University of Minnesota and graduated with a B.A. degree. His curriculums at the university covered a broad spectrum of courses, which provided a solid knowledge basis for his future research. Among the courses, he was

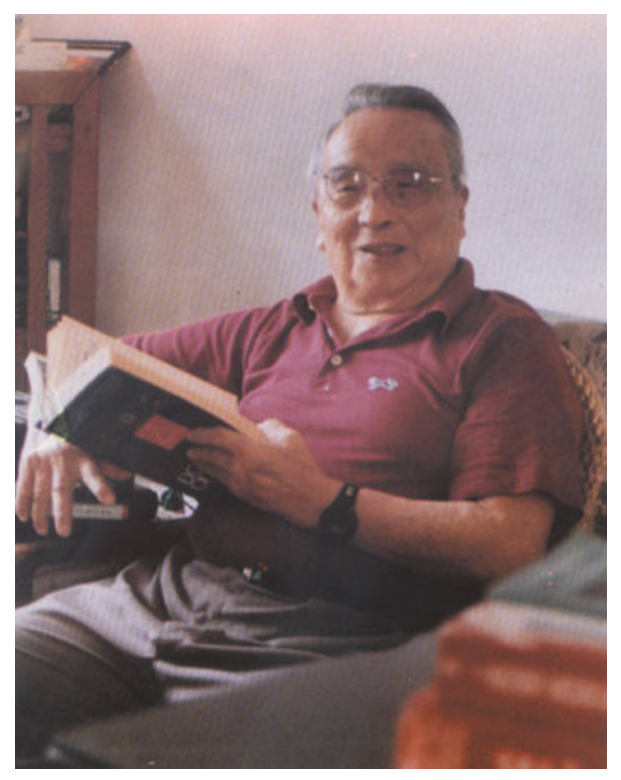

Peisong Tang. (From Selected Works of Tang Pei-Sung, China Esperanto Press, Beijing, 1993. (《汤佩松论文选集》, 中国世界语出版社, 北京, 1993.))

particularly inspired by physical chemistry lectures, which strengthened his interests in the energetics of living matter. After that, he went to John Hopkins to study with Burton Livingtston, but the thesis project that Livingston chose for him did not quite interest him. Unlike some other Chinese students who were humble and always did what they were told to do, Peisong Tang started to perform some experiments to study seed respiration and photosynthesis, meanwhile also working on his thesis project. It was in the Livingston lab where his concept of multiple pathways in respiratory metabolism started to form.

After getting his PhD degree at John Hopkins, and before 
he went to Harvard to work with W. J. Crozier, Peisong Tang spent a summer at the famous Marine Biological Laboratory at Woods Hole in 1930, and returned for another summer in 1931. It was at Woods Hole where he made quite a few friends such as Ralph S. Lillie, Ralph Gerald and W. J. V. Osterhout, whose influences made him decide to choose bioenergetics of cellular and plant respiration and of photosynthesis as his life work.

During his three years at Harvard, he encountered the same problem as he did at John Hopkins-Crozier wanted him to work on the temperature characteristics of seed respiration during germination, a project that did not interest him much. Working harder than ever, Peisong Tang managed to publish quite a few papers on the temperature characteristic project; meanwhile, he also set up experiments of his own, and for the first time discovered cytochrome oxidase in plants in 1932. In 1933, with his commitment to his country, he declined an offer for a position at a New York university, and accepted an invitation from Wuhan University to return to China.

Peisong Tang was quite productive during the first few years at Wuhan University. With the $\$ 2000$ from the university, he managed to set up a small lab for cell and plant physiology, and later published a series of seven papers on the kinetics of cell respiration. Then the eight-year AntiJapanese War began in 1937. The research on cell respiration had to stop, but Peisong Tang never stopped. With his knowledge and experience, he did everything he could to serve the nation at war: first, he converted his lab into a factory making active carbon for gas masks; after Wuhan was occupied, he traveled to the city of Guiyang and helped establishing a medical school there. Later on, like most Chinese scientists, Peisong Tang moved to Kunming. With the relative safety and stability in Kunming, he built a small lab of plant physiology, which also served as an assembly place for young physiologists, many of whom later became the backbone of Chinese physiology.

After the founding of the new China, Peisong Tang finally was able to continue his work on plant respiratory metabolism and photosynthesis. No need to repeatedly count his achievements, but it is important to point out that in his academic life, he was always creative and ahead of his time. One good example is the "Tang-Wang theory of cellular water potential" that he and Zhuxi Wang developed in 1940s. The forerunning concept did not get much attention until 1960s when P. J. Kramer and his colleges published similar theory. Another example is the study by Peisong Tang and Hsiang-Yu $\mathrm{Wu}$ on the adaptive formation of nitrate reductase in rice

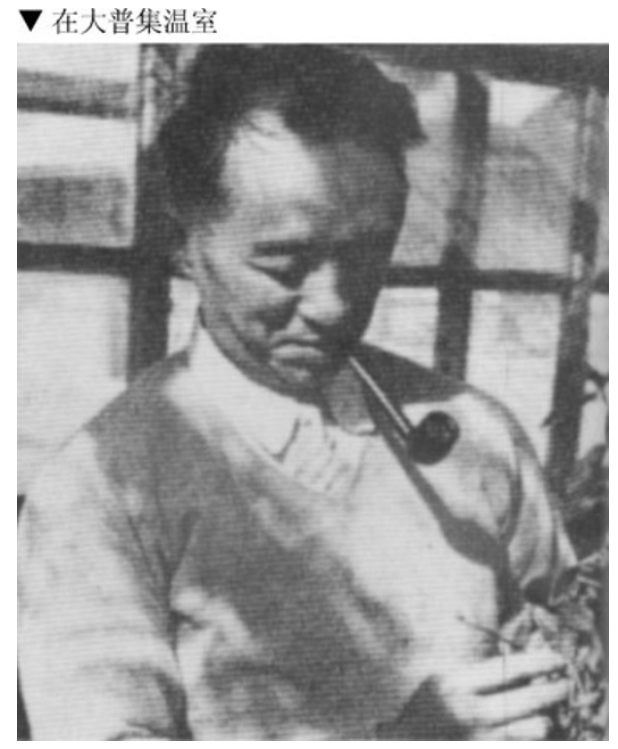

Peisong Tang at his make-shift greenhouse in Kunming (From Selected Works of Tang Pei-Sung, China Esperanto Press, Beijing, 1993. (《汤佩松论文选集》, 中国世界语出版 社, 北京, 1993.))

seedling, the result of which was published in Nature in 1957. It is not only the first report to show that the nitrate reductase is inducible, but also the first proved existence of inducible enzymes in plants.

Even after he retired, the far-seeing vision of Peisong Tang still played an important role in Chinese plant physiology. In the late 1980s, he suggested that inter-disciplinary collaboration was much needed to study the membrane proteins of photosynthesis, so he invited plant physiologist Tingyun Kuang, biophysicists Dongcai Liang and Wenrui Chang over to his house and the four of them had a small meeting to discuss the possibility of collaboration. Over a decade later, after Peisong Tang passed away, Tingyun Kuang's group and Wenrui Chang's group jointly solved the structure of the light harvesting complex II from spinach, which was the first membrane protein structure from China. The result was published in Nature as a cover-story paper in 2004.

To celebrate his $80^{\text {th }}$ birthday in 1983 , Annual Review of Plant Physiology invited Peisong Tang to write an article about his academic life, which he described as "the devious trail of a roaming plant physiologist" in the title of the article. However, with his commitment to his country and his people, and his dedication in pursuing science and truths, he always knew where he was going and never stopped along the way. 